\title{
Interannual variability of the sea-ice-induced salt flux in the Greenland Sea
}

\author{
Leif Toudal, ${ }^{1}$ Max D. Coon ${ }^{2}$ \\ ${ }^{1}$ Danish Centre for Remote Sensing, Technical University of Denmark, DK-2800 Lyngby, Denmark \\ ${ }^{2}$ Northwest Research Associates, 14508 N.E. 20th Street, Bellevue,WA 98007-3027, U.S.A.
}

\begin{abstract}
The Greenland Sea is one of the few places in the World Ocean where deep convection takes place. The convection process is initiated by a density increase originating from rapid cooling and/or a salt flux to the upper layer of the ocean due to brine rejection from ice formation (Rudels, 1990; Visbeck and others, 1995). The predominant ice types in the Greenland Sea are frazil/grease ice and pancake ice. A numerical model has been developed relating ice formation and decay of these ice types as observed by the SMMR and SSM/I microwave radiometers and evaluating their contribution to salt redistribution in the Greenland Sea. The model has been used to calculate spatial distribution of the annual integrated net salt flux to the Greenland Sea from ice production and advection for the period 1979-97.
\end{abstract}

\section{INTRODUCTION}

Sea ice plays an important role in modulating the heat exchange between the ocean and the atmosphere. The heat loss from an ice-covered ocean can be two orders of magnitude smaller than the heat loss from an ice-free ocean during the cold and dark Arctic winter season. Sea ice also modulates the salinity of the underlying ocean, since the salinity of ice is only $5-30 \%$ of the salinity of the sea water around it. This means that the growth of sea ice adds salt, or that melting ice adds fresh water, to the water column. Even though this means that the ocean salinity may rise during periods of ice growth, if the ice does not move, the net effect of this process will be zero increase in salinity at the end of the winter season when the ice has melted. However, if the ice is carried out of the area (e.g. by wind forcing) the fresh water will be removed and the net effect will be an increase in salinity. Similarly, if the ice ends up melting in a different region where less ice formed, the net effect in that area will be a decrease in salinity. This process occurs in polynyas at many places around the Arctic. Ice is formed in the polynya area, and blown off shore by the prevailing winds, eventually leaving behind a substantially salinated ocean. The same process occurs in the Greenland Sea almost every winter in the form of the Odden ice peninsula (Wadhams, 1981; Roach and others, 1993; Carsey and Roach, 1994; Toudal, 1995, 1999; Toudal and others, 1997, 1999a). Ice growth occurs primarily on the northern side of the peninsula (Carsey and Garwood, 1993); the ice is carried southwards by the prevailing northerly winds, and melted when it reaches the warmer waters beyond the polar front to the southeast (Visbeck and others, 1995). A model for salt rejection has been developed by Toudal and Coon (in press), and has been verified using data from the European Subpolar Ocean Project (ESOP) (see Toudal and others, 1999b; Wadhams and Wilkinson, 1999). The purpose of the present paper is to use the salt-flux model

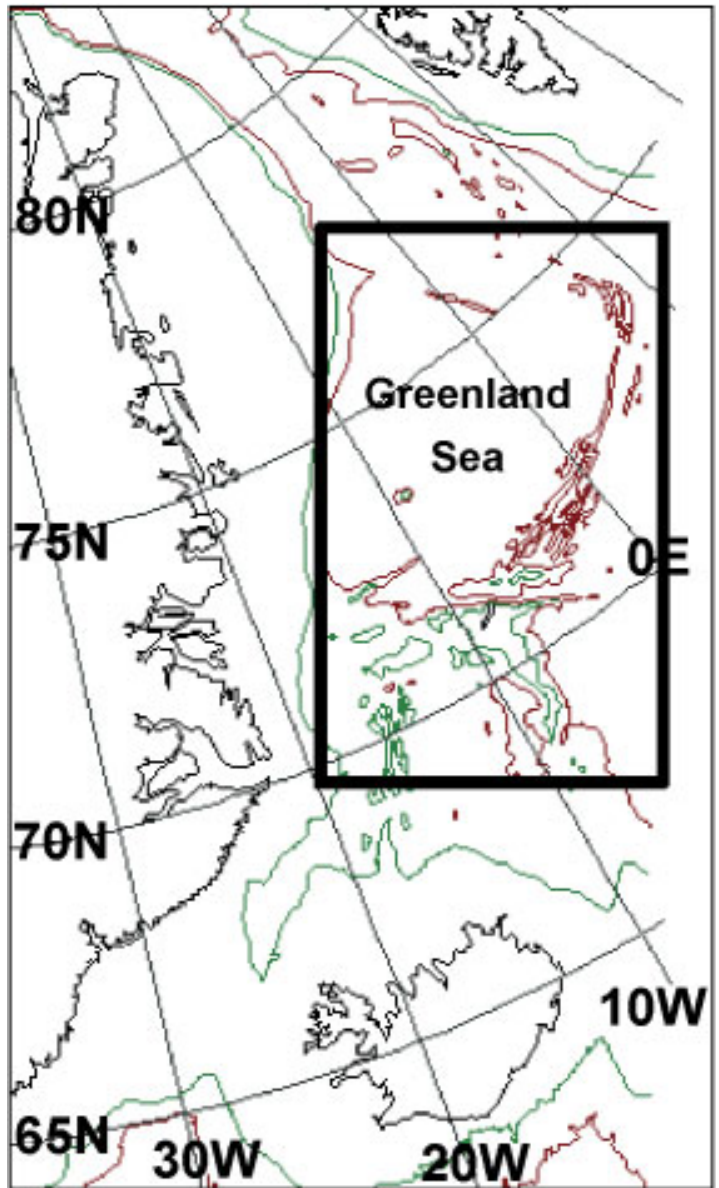

Fig. 1. Outline of the Greenland Sea area and the model area ( rectangular box, thick lines). Vector overlays are coastline, lat.) long. grid with a grid spacing of $5^{\circ}$ latitude and $20^{\circ}$ longitude and 1000 and $2000 \mathrm{~m}$ depth contour showing the Mohns ridge to the right (inside model box area) and the continental-shelf break at the left edge of the model area. 


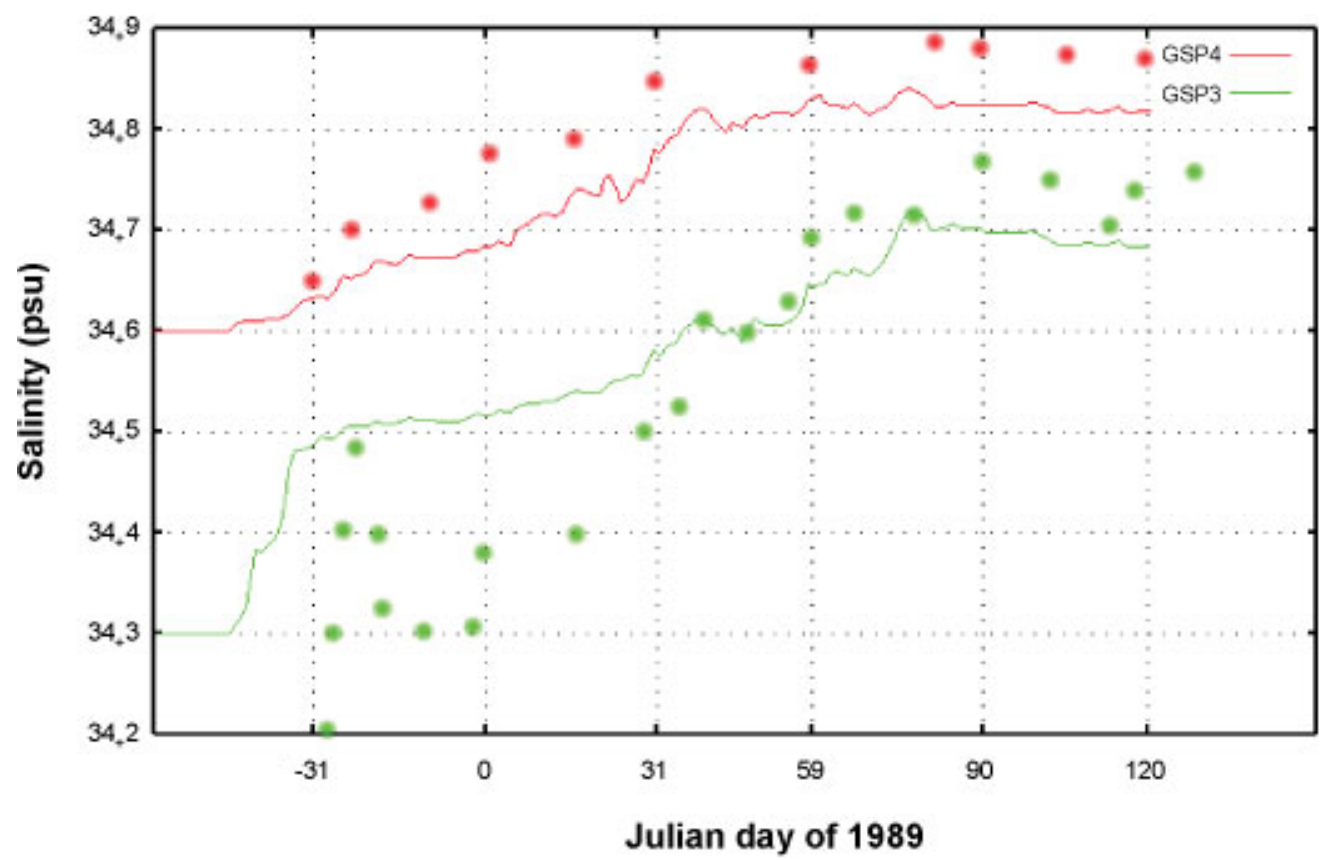

Fig. 2. Modelled and measured salinity time series at two of the GSP mooring sites (GSP3 and GSP4). The full curves are the model calculations assuming a mixed-layer depth of $75 \mathrm{~m}$ for winter 1988/89, and the dots are extracted from the GSP measurements (Carsey and Roach, 1994).

of Toudal and Coon (in press) to quantify the interannual variability of the salt redistribution in the area.

\section{THE MODEL}

The idea of the Toudal and Coon (in press) model is to use ice cover observed daily by the satellite-borne Special Sensor Microwave/Imager (SSM/I) passive-microwave radiometer together with daily-averaged wind fields in an attempt to identify areas of ice growth and areas of ice melt on a daily basis. The observed ice from the previous day is advected by the wind, compared with the next observation, and ice is grown or melted to make the advected field match the observations.

The model utilizes the free-drift approximation to calculate ice advection from European Centre for Medium-range Weather Forecasts (ECMWF) wind data. It subsequently grows or melts ice in every $25 \mathrm{~km} \times 25 \mathrm{~km}$ gridcell to make the advected ice field from the previous time-step (previous day) match the current observation by the SSM/I. Thickness and composition (fraction of pancakes and frazil) of the newly grown ice is determined via a parameterization of results by Alam and Curry (1998).

\section{ICE OBSERVATIONS}

Daily passive-microwave observations from the NIMBUS-7 Scanning Multichannel Microwave Radiometer (SMMR) (1978-87) and from the Defense Meteorological Satellite Program SSM/I instruments (1987-97) are converted to gridded ice concentrations using a tuned version of the Comiso Bootstrap algorithm (Comiso, 1986).

The tuning is performed in order to optimize results in the Greenland Sea region (Fig. 1) where the ice has different characteristics from the ice in the central Arctic (Wadhams and others, 1996). A set of tie points for the SMMR and another set for the SSM/I have been established, and the results were further adjusted in order to match during the overlap period in 1987 when both instruments operated simultaneously for about 6 weeks.

The SMMR and SSM/I data were supplied by the U.S.
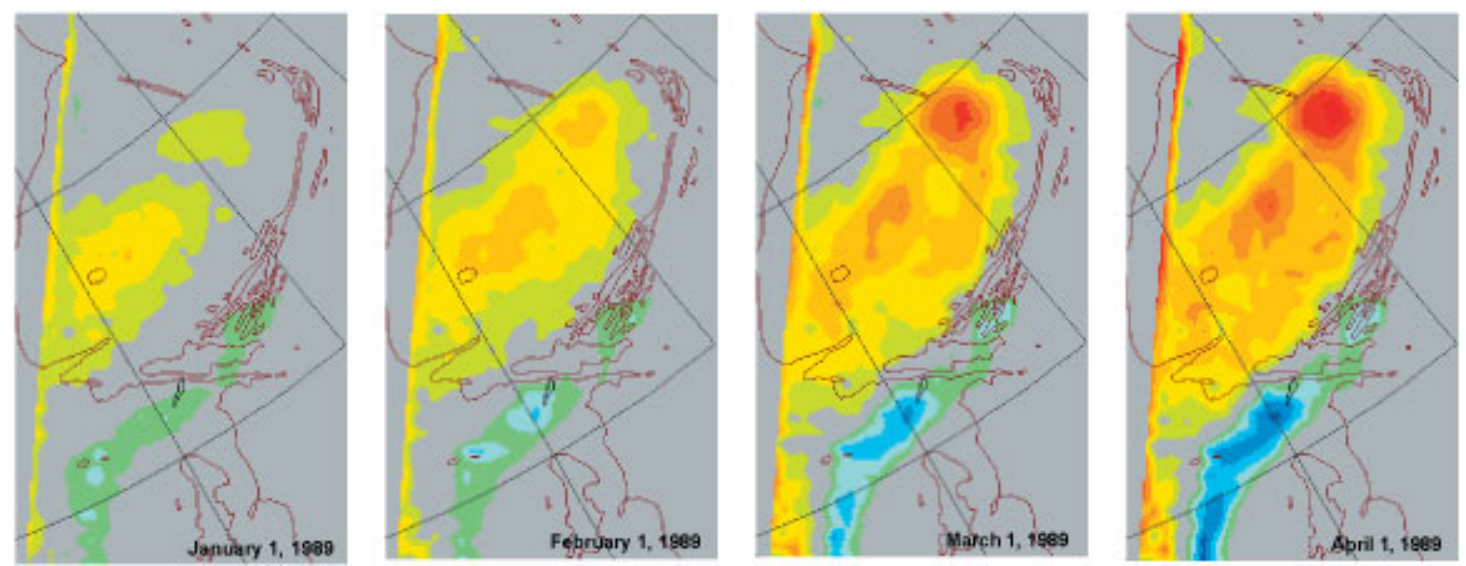

Fig. 3. Stages of salt (and fresh-water) accumulation during winter 1988/99. The colour scale is the same as for Figure 4. 

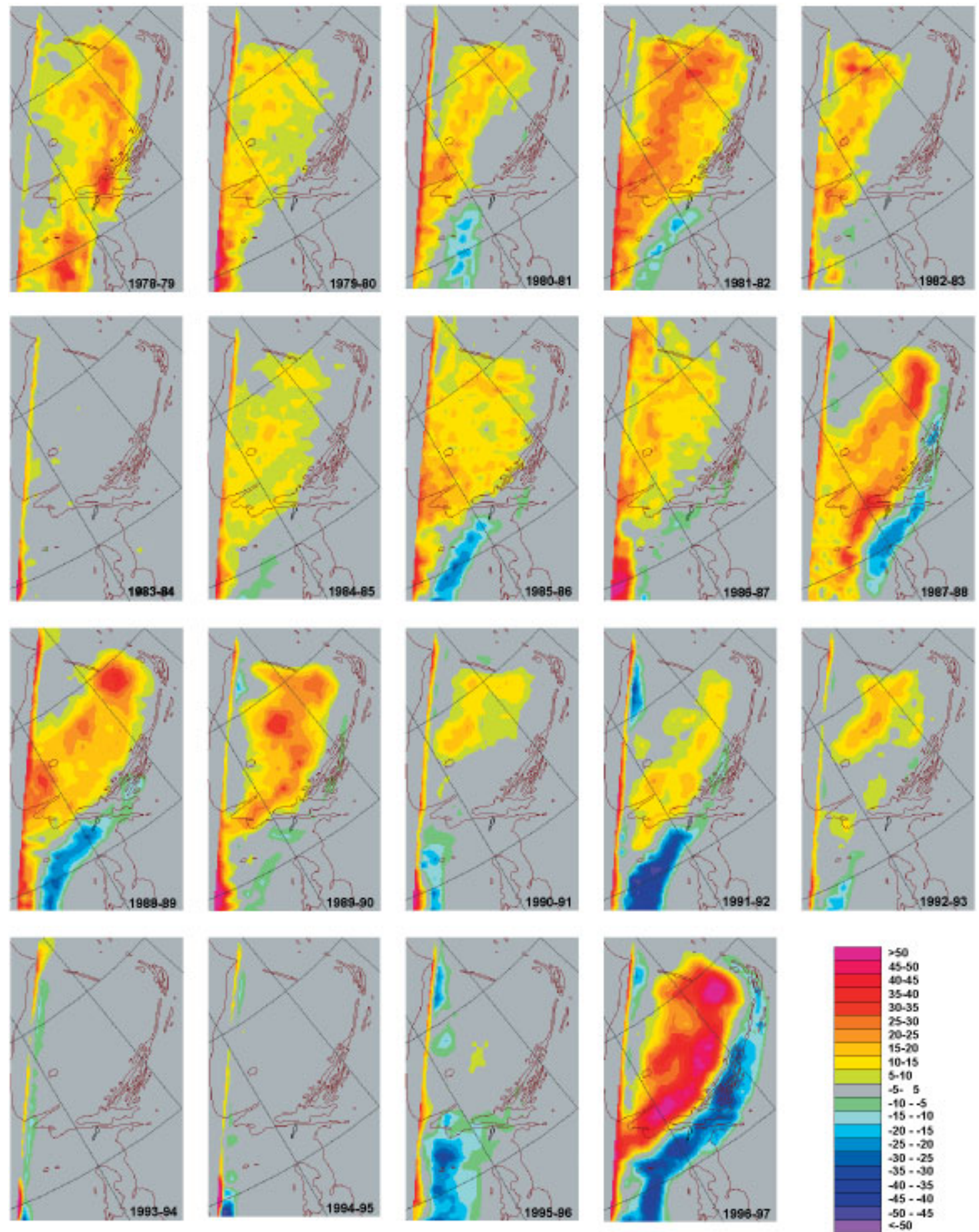

Fig. 4. Net annual salt flux to the Greenland Sea calculated from daily SSM/I observations of the ice cover and ECMWF winds. Units are $\mathrm{kg} \mathrm{salt} \mathrm{m}^{-2}$. Vector overlays are lat./long. grid with a grid spacing of $5^{\circ}$ latitude and $20^{\circ}$ longitude, and $2000 \mathrm{~m}$ depth contour showing the Mohns ridge to the right and the continental-shelf break to the left.

National Snow and Ice Data Center (NSIDC) in the standard SSM/I polar stereographic grid with a grid spacing of $25 \mathrm{~km} \times 25 \mathrm{~km}$ (NSIDG, 1992).

\section{ICE ADVEGTION}

The quantification of advection of the pancakes was accomplished using data from three drift buoys deployed in the Odden area during winter 1996/97 (Wadhams and Wilkinson, 1999). The buoys drifted with the pancake-ice field for 4-8 weeks, and correlation with wind data from the ECMWF led to a drag coefficient and a turning angle. The drag coefficient was in good agreement with drag coefficients inferred from upward-looking acoustic Doppler current profilers during winter 1988/89 (Visbeck and Fischer, 1995).

\section{ICE AGE AND THICKNESS}

The model keeps track of the age distribution of the ice in the way that ice is categorized by its age in days.

The thickness of the ice formed in a $24 \mathrm{~h}$ period is

$$
h=0.053 U-0.229 \text {, }
$$

where $U$ is the $10 \mathrm{~m}$ wind speed in $\mathrm{m} \mathrm{s}^{-1}$. The thickness of ice in the model does not change as the ice gets older. In the model, it is assumed that $35 \%$ of the area covered by new ice in a $24 \mathrm{~h}$ period is pancake ice with a volume concentra- 


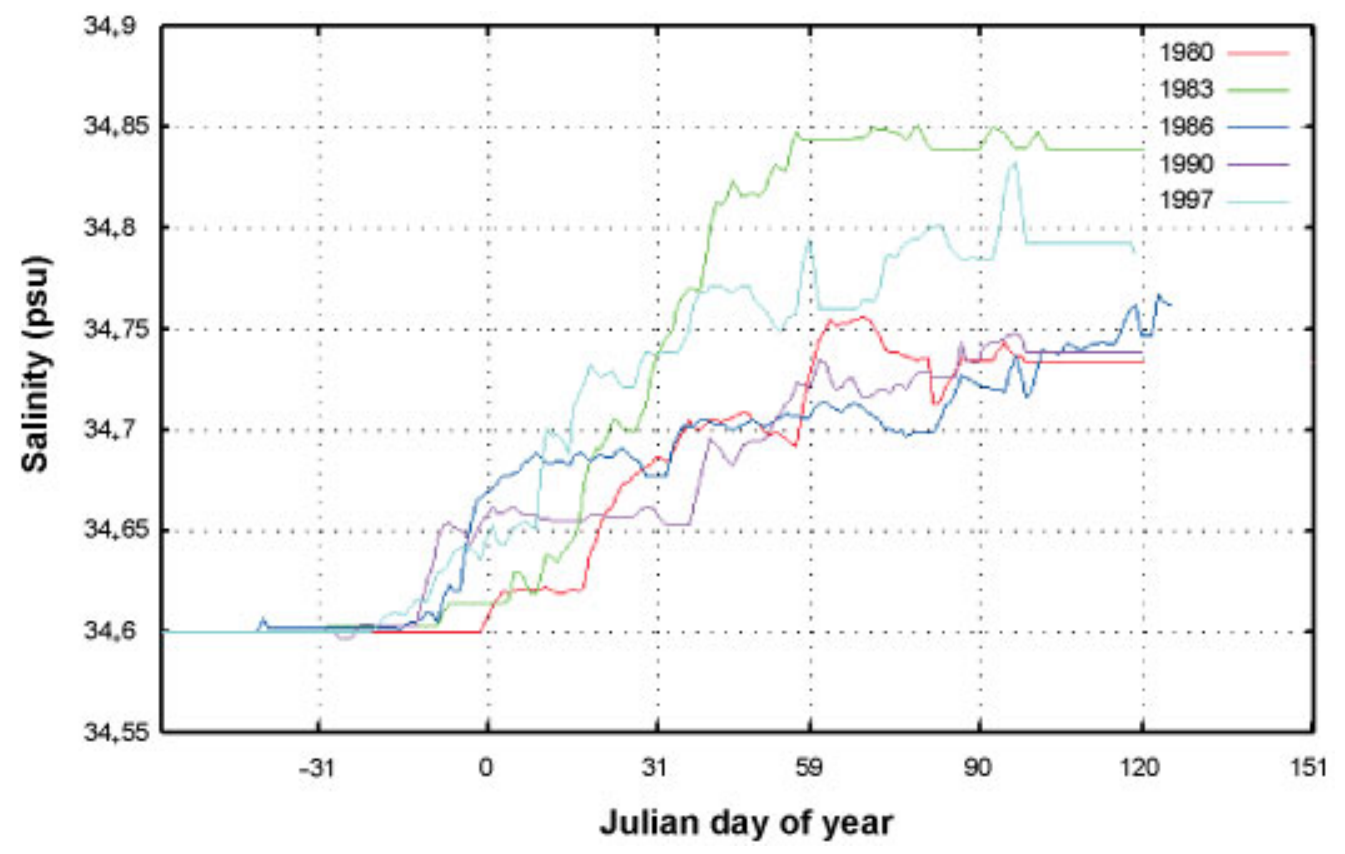

Fig. 5. Modelled salinity, in practical salinity units (psu), of a $100 \mathrm{~m}$ thick mixed layer at $75.1^{\circ} \mathrm{N}, 2.45^{\circ} \mathrm{W}$ for 5 different years. Typical increases of salinity at this position are 0.1-0.25 psu a $a^{-1}$ due to ice formation and advection.

tion of 1.0, and the remaining new-ice area is covered with frazil with a volume concentration of 0.62 .

When the advected ice concentration is larger than the observed ice concentration, ice is melted and the frazil with the lowest volume concentration will be melted first. If, when all frazil is melted, more melt is needed, then the thinnest pancakes will be melted first. Also, the salinity of all remaining ice is reduced until ice has a salinity of $3 \mathrm{ppt}$.

\section{MODEL GALGULATION}

The calculations performed by the model provided each day:

the area concentration of frazil/grease

the thickness of frazil/grease

the volume concentration of frazil/grease

the salinity of frazil/grease

the area concentration of pancakes

the thickness of pancakes

the salinity of pancakes.

The older SMMR data are available only for a 2 day time-step, but the model is parameterized for a 1 day timestep. Therefore, to operate on a 1 day time-step, the 2 day ice concentration from the data was interpolated and the model was run for 1 day time-steps. To perform the same calculation for all data, the newer SSM/I data were treated in a similar manner, i.e. the ice concentration for every other day was interpolated and used to replace the data for the intervening day. For winter 1996/97, the model was run for SSM/I data each day, and the total salt flux was compared with that using 2 day data. The results of the two calculations show very small differences.

Model comparisons with ice-salinity measurements from winter 1988/89

As part of the Greenland Sea Project (GSP Group, 1990), moored current meters were used and temperature/salinity recorded in the Greenland Sea during the period 1988-99, as reported by Roach and others (1993). Roach and others' figure 2 shows salinity time history for the mixed layer (assumed by them to be $75 \mathrm{~m}$ thick) at two different moorings. Figure 2 of this paper compares the model calculations of brine rejection and the measurements reported by Roach and others (1993). It shows the change in salinity of a $75 \mathrm{~m}$ mixed layer resulting from brine rejection at the location of the two moorings calculated by the model. In the model, we cannot know the salinity of the mixed layer at any time, only the change, so the starting salinity for Figure 2 is arbitrary. In addition to the model output, data from figure 2 of Roach and others are shown for some times. The short time fluctuations for the model and measurements are not the same, but the long-term trends are modelled very well, especially since the model was not tuned for this year and the element size for the model is $25 \mathrm{~km}$. This comparison leads us to believe that the brine-rejection calculations for the time period 1979-97 are very good. It is important to note that the selected thickness of the mixed layer in this example, $75 \mathrm{~m}$, does not influence the model calculations of the amount of salt dumped; it is only used to relate this amount to a salinity increase in the upper layer of the ocean. If the mixed layer is thicker, the relative increase will be smaller, and once convection really starts, the convective mechanism will bring the salt to larger depths.

\section{Model calculations for 1979-97}

Results from the model calculations are shown in Figures 3-6.

Figure 3 shows salt-flux maps for different times during the year 1988/89. The amount of salt gradually increases in the northern area as the ice is formed, and later the salinity decreases further south as the ice moves there and melts. Note how the division between the positive (yellow-red) and the negative (blue-green) area lies along the Mohns ridge which also normally separates the cold polar water from the warmer Atlantic water.

Figure 4 shows maps of the total salt flux for each year of 

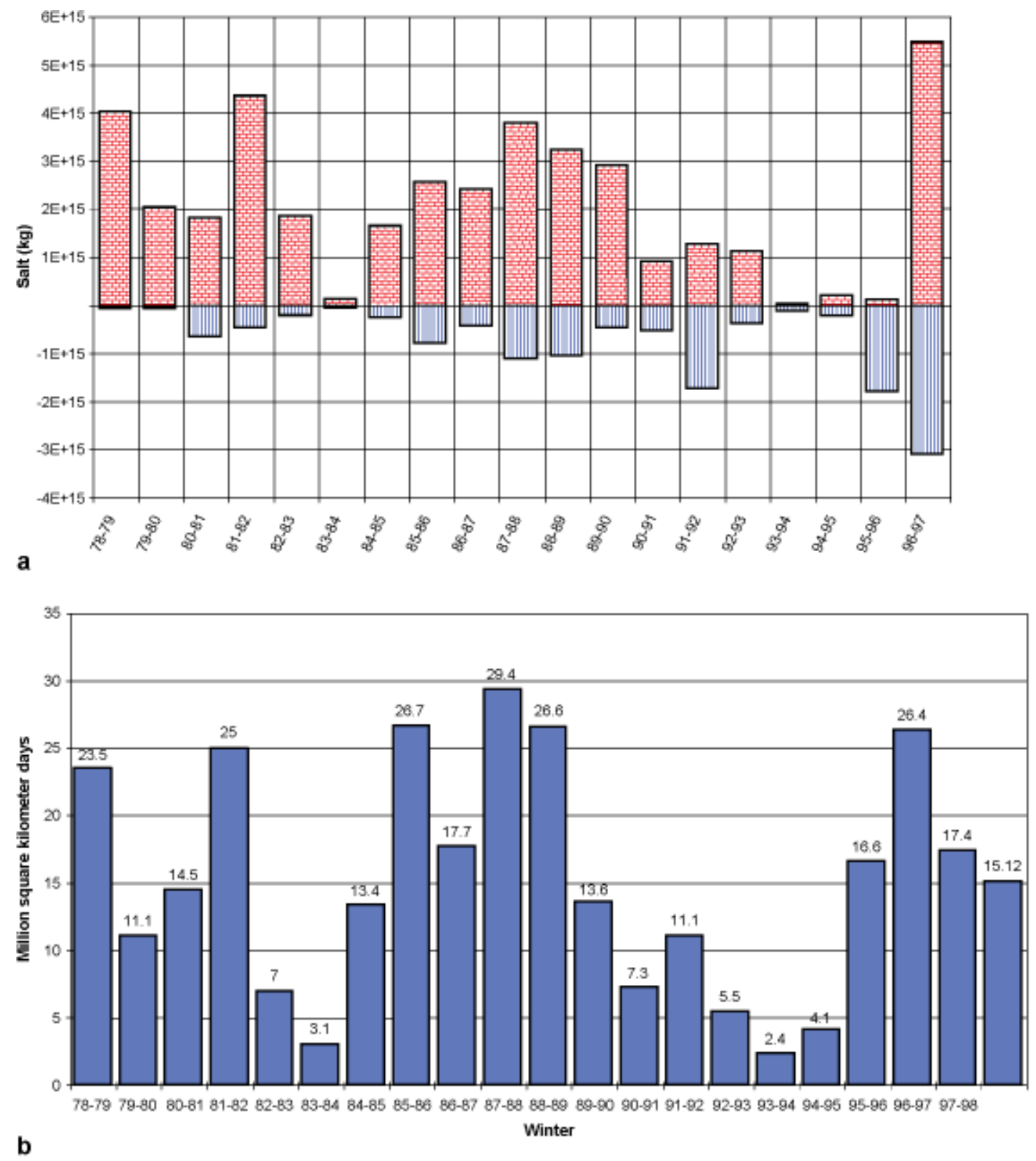

Fig. 6. (a) Integrated amount of salt dumped in the Greenland Sea in the net ice-growth regions for each winter (bricks), and integrated amount of fresh water ( salt equivalent) left inside the area in the net ice-melt regions (vertical hatching). Values are in $\mathrm{kg}$ salt. (b) Integrated ice cover for each of the winters since 1979, in $10^{6} \mathrm{~km}^{2}$ days. The rightmost bar shows the average ice cover for the 20 years $\left(15.12 \times 10^{6} \mathrm{~km}^{2}\right.$ days $)$.

the calculations. Note the large interannual variability, but also the consistent positive salt input to a large ocean area between $72^{\circ}$ and $76^{\circ} \mathrm{N}$ and between $10^{\circ} \mathrm{W}$ and $5^{\circ} \mathrm{E}$. Winter $1996 / 97$ had by far the largest salt redistribution of the 20 years. The observation that the fresh-water deposit area is often smaller and weaker than the salt deposit area reflects the mean wind conditions in the area. During most winters, the prevailing winds from the northeast will carry the ice towards the southwest, and the fresh water will be deposited in the East Greenland Current (EGG) area just to the right of the model grid. One notable exception is winter 1995/96, when large amounts of ice came out from the EGC and melted in the model area (seen as the blue-green patch in the panel for that year). Note also the ice-free winters 1983/ 84, 1993/94 and 1994/95.

Figure 5 shows the variation in salinity of a $100 \mathrm{~m}$ mixed layer for one cell of the model for five different years. This figure shows how the brine rejection can change from year to year.

Figure 6 shows in bar charts the annual salt flux (calcu- lated from the model), and the cumulative ice area of the Odden as determined from SSM/I data. The numbers in the salt-flux chart are areal integrated salt deposits over the entire model grid, and high numbers are in the order of 4000-5000 GT of salt redistribution per year. It is clear that a relationship exists between the salt flux and the cumulative ice area but that there is major variability in the salt flux that must come from some other factor (wind).

\section{DISGUSSION AND SUMMARY}

In the paper, a model has been used to calculate the salt flux produced by the formation of frazil and pancake ice in the Greenland Sea from 1979 to 1997. It is known that the salt flux from ice formation can cause convection in the ocean. Previously, salt production has been estimated assuming that sheet ice was formed from consideration of the temperature. But here we have presented a model that uses SSM/I data as 
input to an ice-formation model which produces frazil and pancake ice and determines the salt flux for this ice production. The model has been tuned previously using measurements for March 1997 (Toudal and Coon, in press). In this paper, the model was used to determine salt flux for 1979-97, and we use mooring data from Roach and others (1993) to compare with model calculations for winter 1988/89. The model cannot determine the mixed-layer salinity, only the change in salinity. The inferred change in salinity of the $75 \mathrm{~m}$ mixed layer for two moorings in the Odden in 1988/89 was in good agreement with observations.

The total annual salt flux for the years 1979-97 was determined and compared with the cumulative ice area and the maximum ice area. The annual salt flux shows variations that differ from those of the cumulative ice area. Therefore, if the salinity of the ocean is a desired result, then it is the salt production that must be determined, and the model presented in this paper seems the best way to do this.

\section{ACKNOWLEDGEMENTS}

We thank P. Wadhams and J. Wilkinson of the Scott Polar Research Institute, Cambridge, U.K., for making available to us an excellent dataset on ice-physics observations in the Odden area collected during the 1997 Jan Mayen cruise of the ESOP-2 project. The research was partly funded by the U.S. Office of Naval Research, partly by a Guest Professorship for M. Coon at the Danish Centre for Remote Sensing and partly by European Commission contract MAS3CT95-0015 (the ESOP-2 project). We thank J. Hesselbjerg at the Danish Meteorological Institute for making the ECMWF wind data available, and the NSIDC for the SMMR and SSM/I data. We thank W. Dierking for his helpful review of the draft paper.

\section{REFERENCES}

Alam, A. and J.A. Curry. 1998. Evolution of new ice and turbulent fluxes over freezing winter leads. F. Geophys. Res., 103(C8), 15,783-15,802.

Carsey, F. D. and R. Garwood. 1993. Identification of modeled ocean plumes in Greenland gyre ERS-1 SAR data. Geophys. Res. Lett., 20(20), 2207-2210.

Carsey, F. D. and A.T. Roach. 1994. Oceanic convection in the Greenland Sea Odden region as interpreted in satellite data. In Johannessen, O. M., R. D. Muench and J. E. Overland, eds. The polar oceans and their role in shaping the global environment: the Nansen Centennial volume. Washington, DC, American Geophysical Union, 211-222. (Geophysical Monograph 85.)

Comiso, J. C. 1986. Characteristics of Arctic winter sea ice from satellite multispectral microwave observations. 7. Geophys. Res., 91 (Cl), 975-994.

Greenland Sea Project (GSP) Group. 1990. The Greenland Sea Project: a venture towards improved understanding of the oceans' role in climate. EOS, 71(24), 750-751, 754-756.

National Snow and Ice Data Center (NSIDC). 1992. DMSP SSM/I brightness temperature and sea ice concentration grids for the polar regions on CD-ROM. Users'guide. Boulder, CO, National Snow and Ice Data Center. (Special Report 1.)

Roach, A. T., K. Aagaard and F. Carsey. 1993. Coupled ice--ocean variability in the Greenland Sea. Atmosphere-Ocean, 31 (3), 319-337.

Rudels, B. 1990. Haline convection in the Greenland Sea. Deep-Sea Res., 37(9), Part A, 1491-1511.

Toudal, L. 1995. Multisensor observations of winter sea ice in the Greenland Sea. SPIE 7., 2319, 126-133.

Toudal, L. 1999. Ice extent in the Greenland Sea 1978-1995. Deep-Sea Res., Ser. II, 46(6-7), 1237-1254.

Toudal, L. P. and M. D. Coon. In press. A sea ice dynamics model for the marginal ice zone with an application to the Greenland Sea. F. Geophys. Res.

Toudal, L., D. Low, H. Valeur and P. Wadhams. 1997. Satellite observations of the Odden ice cover during the winter 1995-1996 (European Subpolar Ocean Program). Lyngby, Technical University of Denmark. Department of Electromagnetic Systems. (Tech. Rep. R-656.)

Toudal, L., K. Q. Hansen, H. Valeur, P. Wadhams, E. Aldworth and J. C. Comiso. 1999a. Mapping of ice in the Odden by satellite and airborne remote sensing. Deep-Sea Res., Ser. II, 46(6-7), 1255-1274.

Toudal, L. and 15 others. 1999b. Sea ice physics. ESOP2 final report. Bergen, University of Bergen. (EC contract MAS3-CT95-0015.)

Visbeck, M. and J. Fischer. 1995. Sea surface conditions remotely sensed by upward-looking ADCPs. F. Atmos. Oceanic Technol., 12(1), 141-149.

Visbeck, M., J. Fischer and F. Schott. 1995. Preconditioning the Greenland Sea for deep convection: ice formation and ice drift. 7. Geophys. Res., $\mathbf{1 0 0}$ (C9), 18,489-18,502.

Wadhams, P. 1981. The ice cover in the Greenland and Norwegian Seas. Rev. Geophys. Space Phys., 19(3), 345-393.

Wadhams, P. and J.P. Wilkinson. 1999. The physical properties of sea ice in the Odden tongue. Deep-Sea Res., Ser. II, 46(6-7), 1275-1300.

Wadhams, P. and 8 others. 1996. The development of the Odden ice tongue in the Greenland Sea during winter 1993 from remote sensing and field observations. f. Geophys. Res., 101 (C8), 18,213-18,235. 